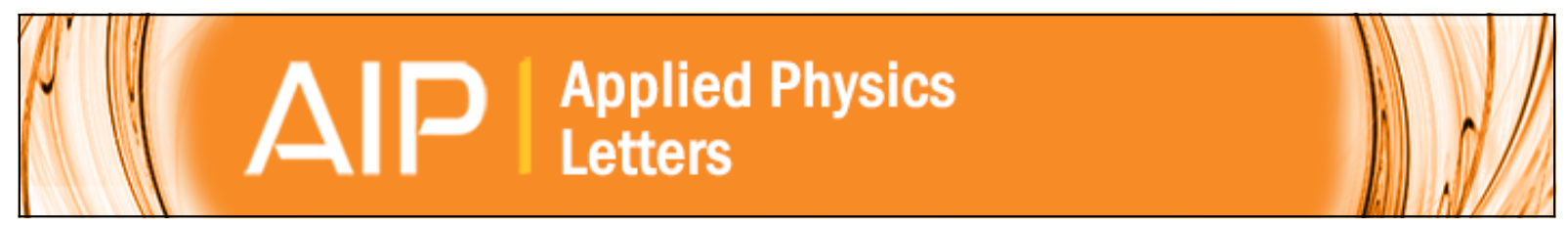

\title{
Magnetic anisotropy study of ion-beam synthesized cobalt nanocrystals
}

J.-K. Lee, M. F. Hundley, J. D. Thompson, R. K. Schulze, H. S. Jung, J. A. Valdez, M. Nastasi, and X. Zhang

Citation: Applied Physics Letters 89, 182502 (2006); doi: 10.1063/1.2364176

View online: http://dx.doi.org/10.1063/1.2364176

View Table of Contents: http://scitation.aip.org/content/aip/journal/apl/89/18?ver=pdfcov

Published by the AIP Publishing

\section{Articles you may be interested in}

Enhancement of the magnetic interfacial exchange energy at a specific interface in $\mathrm{NiFe} / \mathrm{CoO} / \mathrm{Co}$ trilayer thin films via ion-beam modification

J. Appl. Phys. 115, 073901 (2014); 10.1063/1.4865569

Asymmetric magnetization reversal process in Co nanohill arrays

J. Appl. Phys. 106, 103906 (2009); 10.1063/1.3254195

Correlating exchange bias with magnetic anisotropy in ion-beam bombarded $\mathrm{NiFe} / \mathrm{Mn}$-oxide bilayers

J. Appl. Phys. 104, 123908 (2008); 10.1063/1.3040719

Preparation and magnetic properties of hollow nano-spheres of cobalt and cobalt oxide: Drastic cooling-field effects on remnant magnetization of antiferromagnet

Appl. Phys. Lett. 85, 5287 (2004); 10.1063/1.1827329

Enhancement of magnetic coercivity and macroscopic quantum tunneling in monodispersed $\mathrm{Co} / \mathrm{CoO}$ cluster assemblies

Appl. Phys. Lett. 75, 3856 (1999); 10.1063/1.125479

\section{NEW! Asylum Research MFP-3D Infinity ${ }^{\text {TM }}$ AFM}

Unmatched Performance, Versatility and Support

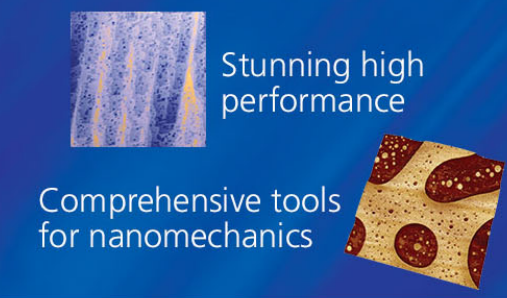

Simpler than ever to GetStarted ${ }^{\mathrm{T}}$

Widest range of accessories

for materials science and bioscience

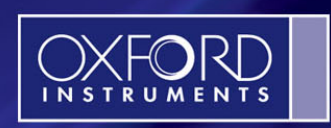

The Business of Science ${ }^{2}$ 


\title{
Magnetic anisotropy study of ion-beam synthesized cobalt nanocrystals
}

\author{
J.-K. Lee, ${ }^{\text {a) }}$ M. F. Hundley, J. D. Thompson, R. K. Schulze, H. S. Jung, ${ }^{\text {b) }}$ \\ J. A. Valdez, and M. Nastasi \\ Materials Science \& Technology Division, Los Alamos National Laboratory, Los Alamos, \\ New Mexico 87544 \\ X. Zhang \\ Department of Mechanical Engineering, Texas A\&M University, College Station, Texas 77843
}

(Received 19 June 2006; accepted 31 August 2006; published online 30 October 2006)

\begin{abstract}
The magnetic properties of Co nanocrystals in crystalline $\mathrm{Al}_{2} \mathrm{O}_{3}$ and amorphous $\mathrm{SiO}_{2}$ are investigated. In contrast to the $\mathrm{SiO}_{2}$ matrix, the $\mathrm{Al}_{2} \mathrm{O}_{3}$ matrix provides higher magnetic anisotropy and coercive field for Co nanocrystals. Using x-ray photoemission spectroscopy, it is found that a $\mathrm{CoAl}_{2} \mathrm{O}_{4}$ layer forms in Co implanted region. Transmission electron microscopy shows that this $\mathrm{CoAl}_{2} \mathrm{O}_{4}$ layer is grown epitaxially around Co nanocrystals. The higher coercive field of the Co nanocrystals in $\mathrm{Al}_{2} \mathrm{O}_{3}$ is attributed to the presence of antiferromagnetic $\mathrm{CoAl}_{2} \mathrm{O}_{4}$ layers. (C) 2006 American Institute of Physics. [DOI: 10.1063/1.2364176]
\end{abstract}

Recently, increasing scientific and technological interests have been placed on the magnetism of nanostructured materials due to their intriguing properties and their potential applications for future ultrahigh density recording media., Previous studies on the magnetism of the nanostructured materials have shown that one of the key challenges is maintaining stable magnetic properties against thermal fluctuations. Ferromagnetic nanosized particles possess reduced magnetic anisotropy and stability, leading to the superparamagnetic state. ${ }^{3,4}$ Magnetic interactions between ferromagnetic nanocrystals and antiferromagnetic coating layers have been exploited to modify the magnetic properties of nanocrystals. The hybrid structure of a Co core and a $\mathrm{CoO}$ shell can significantly enhance the magnetic anisotropy and temperature stability of nanostructured Co.,

Ion implantation followed by thermal annealing has been utilized to embed various magnetic particles inside a matrix. However, most previous studies used an amorphous matrix or high annealing temperatures providing bigger particles. ${ }^{7-9}$ Hence, the role of the matrix crystal structure or the magnetic stability of ion beam synthesized nanocrystals has been neglected. In the present study, we investigate the effect of matrix structure on the evolution of Co nanocrystals and their magnetic properties using amorphous $\mathrm{SiO}_{2}$ and single crystalline $\mathrm{Al}_{2} \mathrm{O}_{3}$ as matrix materials. Our study shows that both Co nanocrystals and $\mathrm{CoAl}_{2} \mathrm{O}_{4}$ grow with a crystallographic relationship to $\mathrm{Al}_{2} \mathrm{O}_{3}$ and that the coexistence of these phases increases their magnetic anisotropy.

Crystalline (0001) $\mathrm{Al}_{2} \mathrm{O}_{3}$ substrates were implanted with $40 \mathrm{keV} \mathrm{Co}{ }^{+}$at a dose of $3 \times 10^{16} / \mathrm{cm}^{2}$. As a companion set, optical grade amorphous silica $\left(a-\mathrm{SiO}_{2}\right)$ substrates were implanted with the same dose of Co at energy of $25 \mathrm{keV}$ to ensure the same projected range in both substrates. ${ }^{10}$ Subsequently, these two sets of samples were annealed at $700{ }^{\circ} \mathrm{C}$ in a vacuum of $2 \times 10^{-6}$ torr. The concentration profiles of implanted ions were monitored by Rutherford backscattering spectrometry.

\footnotetext{
a) Author to whom correspondence should be addressed; electronic mail: jklee@lanl.gov

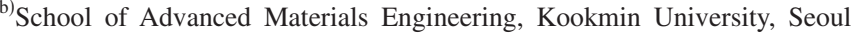
136-702, Korea.
}

Magnetic measurements were carried out with a superconducting quantum interference device magnetometer. The magnetic field was parallel to the surface of substrates. Grazing incidence $\mathrm{x}$-ray diffraction (XRD) measurements were made for the as-implanted and annealed samples. The morphology and crystallographic information of Co nanocrystals were analyzed by transmission electron microscopy (TEM; Philips, model CM 30). The oxidation state of Co was analyzed with the aid of x-ray photoemission spectroscopy (XPS; PHI5600 ESCA system). The C $1 s$ and Si $2 p$ peaks were used to calibrate the binding energy of spectra.

Figure 1 shows the magnetic hysteresis loops $M(H)$ of Co nanocrystals in crystalline $\mathrm{Al}_{2} \mathrm{O}_{3}$ and amorphous $\mathrm{SiO}_{2}$, which were annealed at $700{ }^{\circ} \mathrm{C}$. The measurements were performed at $4 \mathrm{~K}$. Clear magnetic hysteresis loops are observed for both samples. The magnetic moment per cobalt atom is $1.25 \mu_{B}$ for the $\mathrm{SiO}_{2}$ matrix and $1.14 \mu_{B}$ for the $\mathrm{Al}_{2} \mathrm{O}_{3}$ matrix, which are comparable in both substrates. However, the two samples show a big difference in coercive field, with the Co nanocrystals in the $\mathrm{Al}_{2} \mathrm{O}_{3}$ matrix being significantly larger; at $10 \mathrm{~K}$, the coercive field of 850 Oe for the $\mathrm{Al}_{2} \mathrm{O}_{3}$ matrix is two times larger than that for the $\mathrm{SiO}_{2}$ matrix. The magnetic field corresponding to the saturated magnetization is also higher in $\mathrm{Al}_{2} \mathrm{O}_{3}$ than in $\mathrm{SiO}_{2}$ by a factor of 2. This indicates that the $\mathrm{Al}_{2} \mathrm{O}_{3}$ matrix provides an additional mag-

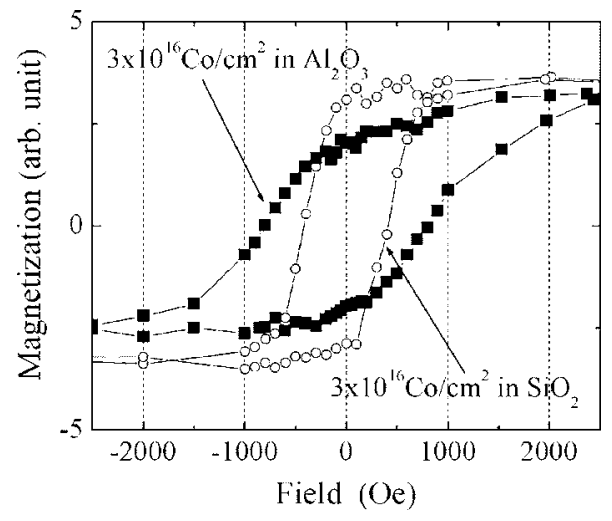

FIG. 1. In plane magnetization of $\mathrm{Co}$ nanocrystals embedded in $\mathrm{Al}_{2} \mathrm{O}_{3}$ and $\mathrm{SiO}_{2}$ at $10 \mathrm{~K}$. 


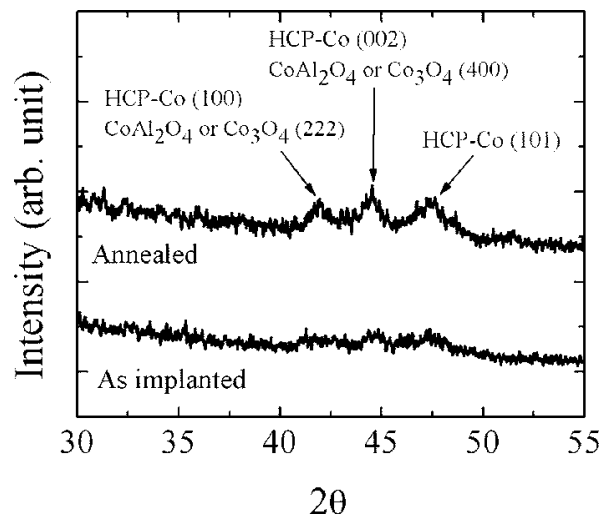

FIG. 2. Grazing incidence x-ray diffraction patterns of $3 \times 10^{16} \mathrm{Co} / \mathrm{cm}^{2}$ implanted $\mathrm{Al}_{2} \mathrm{O}_{3}$ for as-implanted and $700{ }^{\circ} \mathrm{C}$ annealed samples.

netic anisotropy to Co nanocrystals, which increases their magnetic stability.

The higher coercive field of Co nanocrystals in crystalline $\mathrm{Al}_{2} \mathrm{O}_{3}$ is intriguing. In ferromagnetic nanocrystals, the magnetic anisotropy mainly depends on their size. ${ }^{3}$ However, the TEM micrographs of two samples (not shown) show similar size of Co nanocrystals in amorphous $\mathrm{SiO}_{2}$ and crystalline $\mathrm{Al}_{2} \mathrm{O}_{3}$, indicating that the high magnetic anisotropy of Co nanocrystals inside the crystalline $\mathrm{Al}_{2} \mathrm{O}_{3}$ is not due to a size effect. Another possible source for high magnetic anisotropy is the surface layer of Co nanocrystals., ${ }^{5,11,12}$ The previous studies imply that there may be an antiferromagnetic surface layer on the Co nanocrystals of crystalline $\mathrm{Al}_{2} \mathrm{O}_{3}$. Figure 2 shows the grazing incidence XRD patterns of asimplanted and annealed $\mathrm{Co}$ in $\mathrm{Al}_{2} \mathrm{O}_{3}$. Hexagonal closed packed (hcp) Co and Co-containing oxides with a spinel structure are observed in the XRD patterns of the asimplanted sample. In the annealed sample, the intensity of peaks corresponding to hcp structure increases, suggesting the growth of hcp Co nanocrystals during annealing. Also, the peak attributed to (400) Co-spinel points to the presence of a spinel compound, either $\mathrm{Co}_{3} \mathrm{O}_{4}$ or $\mathrm{CoAl}_{2} \mathrm{O}_{4}$. XPS measurements confirm the presence of $\mathrm{Co}$ spinel and help to distinguish between the $\mathrm{Co}_{3} \mathrm{O}_{4}$ and $\mathrm{CoAl}_{2} \mathrm{O}_{4}$ phases. Figure 3 shows the XPS of the Co $2 p$ level in as-implanted and annealed $\mathrm{Al}_{2} \mathrm{O}_{3}$. While metallic $\mathrm{Co}$ is prevalent in the asimplanted state, the XPS data from the annealed samples show a mixture of metallic $\mathrm{Co}$ and $\mathrm{CoAl}_{2} \mathrm{O}_{4}$. The peak at $781.7 \mathrm{eV}$ and strong satellite at $786.8 \mathrm{eV}$ from the annealed sample indicate that the spinel phase is $\mathrm{CoAl}_{2} \mathrm{O}_{4}$ instead of $\mathrm{Co}_{3} \mathrm{O}_{4} \cdot{ }^{13}$ It is noted that XPS data of as-implanted samples mainly show metallic Co whereas their XRD data show rather weak signals. This indicates that most of implanted Co ions form very small Co nanocrystals in as-implanted state. ${ }^{14}$ When the size of the Co nanocrystals is too small or their crystallinity is low, the characterization tools with different probing scales provide the different signal intensities.

How can a layer of $\mathrm{CoAl}_{2} \mathrm{O}_{4}$ form in the Co implanted region? $\mathrm{CoAl}_{2} \mathrm{O}_{4}$ formation from the reaction of $\mathrm{Co}$ and $\mathrm{Al}_{2} \mathrm{O}_{3}$ is thermodynamically unfavorable at $700{ }^{\circ} \mathrm{C}$, with a positive heat of formation of $62.0 \mathrm{kcal} / \mathrm{mol}$. However, for the case of Co implantation, an excess nonequilibrium concentration of $\mathrm{O}$ interstitials can be formed, which can influence the reaction path. Photoemission spectra of $\mathrm{O} 1 s$ for as-implanted and annealed $\mathrm{Al}_{2} \mathrm{O}_{3}$ in Fig. 3(b) show that the annealing increases the binding energy of $\mathrm{O}$. This change in
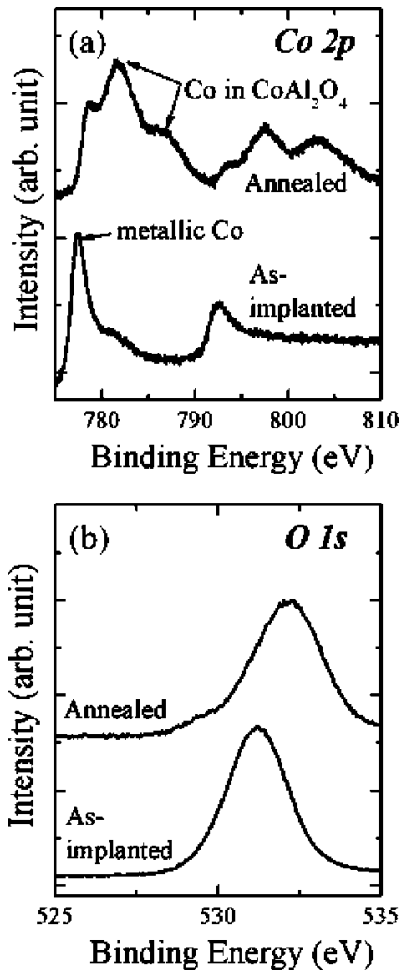

FIG. 3. (a) Co $2 p$ core and (b) $\mathrm{O} 1 s$ core levels of X-ray photoemission spectra (XPS) data of for as-implanted and $700{ }^{\circ} \mathrm{C}$ annealed samples.

the binding energy of $\mathrm{O}$ proves the presence of $\mathrm{O}$ interstitials in the as-implanted $\mathrm{Al}_{2} \mathrm{O}_{3}$ matrix and their recombination with cations during the annealing process. Therefore, the real reaction that must be considered is between atomic $\mathrm{O}$, metallic $\mathrm{Co}$, and $\mathrm{Al}_{2} \mathrm{O}_{3}$ matrix and their reaction has a negative heat of formation of $-555.7 \mathrm{kcal} / \mathrm{mol}$ for $\mathrm{CoAl}_{2} \mathrm{O}_{4}$. This indicates that the use of implanted $\mathrm{Co}$ and dissociated $\mathrm{O}$ interstitial changes the thermodynamic reaction for $\mathrm{CoAl}_{2} \mathrm{O}_{4}$ from an endothermic to exothermic process and makes the formation of $\mathrm{CoAl}_{2} \mathrm{O}_{4}$ possible during the ion implantation and subsequent annealing process.

Cross-sectional TEM was performed on Co-implanted and $700{ }^{\circ} \mathrm{C}$ annealed $\mathrm{Al}_{2} \mathrm{O}_{3}$ specimens to investigate their microstructures. Two sets of cross-sectional TEM specimens were examined with different diffraction zone axes, namely, [1010] and [2110]. The TEM results along the [2110] zone axis are presented in Fig. 4. As shown in Fig. 4(a), Co nanocrystals with a size of $3.8 \pm 0.8 \mathrm{~nm}$ are distributed within the matrix. The size of nanocrystals in TEM images were calibrated by counting the lattice fringes of $\mathrm{Al}_{2} \mathrm{O}_{3}$ and Co nanocrystals. The spatial resolution of this method was approximately $0.15 \mathrm{~nm}$, which was much smaller than the size of Co nanocrystals. Selected area diffraction patterns, shown in Fig. 4(b), reveal three sets of diffraction spots, indicating the existence of three different materials. The distinctive diffraction spots marked with subscripts $\mathrm{A}$ and $\mathrm{B}$ represent the diffraction patterns from $\mathrm{Al}_{2} \mathrm{O}_{3}$ and $\mathrm{CoAl}_{2} \mathrm{O}_{4} \cdot{ }^{15}$ Another set of diffraction spots is indexed to be (0002) hcp Co, lying vertically along the center spot. These observations imply that the $\mathrm{CoAl}_{2} \mathrm{O}_{4}$ layer is epitaxially related to $\mathrm{Al}_{2} \mathrm{O}_{3}$ and that the Co nanocrystals are strongly textured with the $\mathrm{Al}_{2} \mathrm{O}_{3}$ and $\mathrm{CoAl}_{2} \mathrm{O}_{4}$. The epitaxial relationship is clearly shown in the magnified diffraction pattern of Fig. 4(b). Three overlaid diffraction spots have the orientation relationship of $\{0006\} \mathrm{Al}_{2} \mathrm{O}_{3}\left\|\{111\} \mathrm{CoAl}_{2} \mathrm{O}_{4}\right\|\{0002\} \mathrm{Co}$. The interplanar 

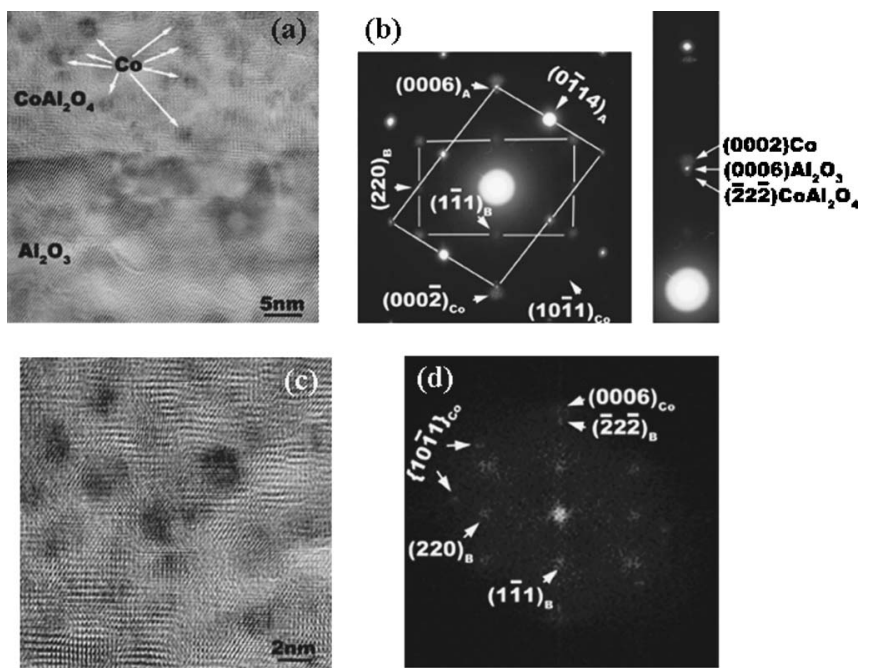

FIG. 4. Cross-sectional high resolution TEM micrographs of 3 $\times 10^{16} \mathrm{Co} / \mathrm{cm}^{2}$ implanted $\mathrm{Al}_{2} \mathrm{O}_{3}$ for as-implanted and $700{ }^{\circ} \mathrm{C}$ annealed samples, (a) HRTEM image showing both unimplanted and implanted regions, (b) diffraction pattern obtained from the same region of (a), (c) HRTEM image of implanted region, and (d) fast Fourier transformation from the same region of $(\mathrm{d})$.

spacing of these atomic planes in bulk crystals are as follows: $d$ (0006) of $\mathrm{Al}_{2} \mathrm{O}_{3}=2.165 \AA, d$ (222) of $\mathrm{CoAl}_{2} \mathrm{O}_{4}$ $=2.34 \AA$, and $d$ (0002) of $\mathrm{Co}=2.06 \AA$. The dark spots in high-resolution transmission electron microscopy (HRTEM) micrograph of Fig. 4(c) show Co nanocrystals embedded in a $\mathrm{CoAl}_{2} \mathrm{O}_{4}$ matrix. As shown in Fig. 4(d), the fast Fourier transformation from the same region shows that the orientation relationship between $\mathrm{Co}$ and $\mathrm{CoAl}_{2} \mathrm{O}_{4}$ is the same as that described in Fig. 4(b). This is analogous to previous structural studies showing the lattice match between the (111) plane of $\mathrm{ZnAl}_{2} \mathrm{O}_{4}$ and the (0001) plane of $\mathrm{ZnO}^{16,17}$ The fast Fourier transformation from individual nanocrystals shows the diffraction patterns similar to Fig. 4(d). Since the implanted Co ions form the small Co nanocrystals during the implantation process, ${ }^{14}$ this indicates that the preexistent $\mathrm{Co}$ nanocrystals provided seeds for the growth of $\mathrm{CoAl}_{2} \mathrm{O}_{4}$ layer.

The peak concentration of implanted $\mathrm{Co}$ in $\mathrm{Al}_{2} \mathrm{O}_{3}$ is 11 at. \%. The amount of Co in Co nanocrystals calculated based on the density of nanocrystals observed in Fig. 4(a) is roughly 7 at. \%, which indicates that roughly 24 at. \% of the $\mathrm{Al}_{2} \mathrm{O}_{3}$ matrix is expected to convert to $\mathrm{CoAl}_{2} \mathrm{O}_{4}$ after annealing. Given that the percolation threshold is $28 \mathrm{vol} \%$ for spherical objects in three dimensions, we conclude that Co nanocrystals are coated by a $\mathrm{CoAl}_{2} \mathrm{O}_{4}$ layer and that the $\mathrm{Co}-\mathrm{CoAl}_{2} \mathrm{O}_{4}$ hybrid nanocrystals are interconnected three dimensionally in the implanted region of the $\mathrm{Al}_{2} \mathrm{O}_{3}$ matrix. This distribution picture of each phase $\left(\mathrm{Co}, \mathrm{CoAl}_{2} \mathrm{O}_{4}\right.$, and $\mathrm{Al}_{2} \mathrm{O}_{3}$ ) allows us to understand the increased coercive field and magnetic anisotropy of Co nanocrystals in $\mathrm{Al}_{2} \mathrm{O}_{3}$. If the nanostructured ferromagnetic materials are coated by antiferromagnetic layers, the magnetic properties of the antiferromagnetic material may be dominated by interfacial exchange interactions between the ferromagnetic and antifer- romagnetic materials, leading to anomalous magnetic behavior. ${ }^{5,6,11,12}$ Since $\mathrm{CoAl}_{2} \mathrm{O}_{4}$ is an antiferromagnetic material, ${ }^{18,19}$ the magnetic interaction between Co nanocrystal and $\mathrm{CoAl}_{2} \mathrm{O}_{4}$ at the interface can change the magnetic properties of Co nanocrystals. The effect of the interfacial exchange interactions is determined by the competition between the Zeeman energy, anisotropy energy, and exchange energy of composites. When the diameter of Co nanocrystals is smaller than $12 \mathrm{~nm}$ and the thickness of the antiferromagnetic layer is comparable to it, the Zeeman energy of the ferromagnetic component and the exchange energy at the interface dominate the anisotropy energy of antiferromagnetic layer. ${ }^{20}$ Then, the spins in the antiferromagnetic layers rotate under the application of external field and the magnetic anisotropy and coercive field of the system increase, which is observed in this study.

This work was supported by the U.S. Department of Energy Office, Basic Energy Sciences and Laboratory Directed Research and Development at LANL. The authors thank the technical staff of the Los Alamos Ion Beam Materials Laboratory.

${ }^{1}$ T. Thurn-Albrecht, J. Schotter, G. A. Kastle, N. Emley, T. Shibauchi, L. Krusin-Elbaum, K. Guarini, C. T. Black, M. T. Tuominen, and T. P. Russell, Science 290, 2126 (2000).

${ }^{2}$ S. Rusponi, T. Cren, N. Weiss, M. Epple, P. Buluschek, L. Claude, and H. Brune, Nat. Mater. 2, 546 (2003).

${ }^{3}$ D. L. Leslie-Pelecky and R. D. Rieke, Chem. Mater. 8, 1770 (1996).

${ }^{4}$ T. Jonsson, P. Nordblad, and P. Svedlindh, Phys. Rev. B 57, 497 (1998).

${ }^{5}$ D. L. Peng, K. Sumiyama, T. Hihara, S. Yamamuro, and T. J. Konno, Phys. Rev. B 61, 3103 (2000).

${ }^{6}$ T. Yamauchi and K. Shiiki, Jpn. J. Appl. Phys., Part 1 41, 5982 (2002).

${ }^{7}$ E. Cattaruzza, F. Conella, G. Mattei, P. Mazzoldi, D. Gatteschi, C. Sangregorio, M. Falconieri, G. Salvetti, and G. Battaglin, Appl. Phys. Lett. 73, 1176 (1998).

${ }^{8}$ A. Meldrum, L. A. Boatner, and K. Sorge, Nucl. Instrum. Methods Phys. Res. B 207, 37 (2003).

${ }^{9}$ O. Cintora-Gonzalez, D. Muller, C. Estournes, M. Richard-Plouet, R. Poinsot, J. J. Grob, and J. Guille, Nucl. Instrum. Methods Phys. Res. B 178, 144 (2001).

${ }^{10}$ J. F. Ziegler, J. P. Biersack, and U. Littmark, The Stopping and Range of Ions in Solids (Pergamon, New York, 1985), pp. 1-139.

${ }^{11}$ V. Skumryev, S. Stoyanov, Y. Zhang, G. Hadjipanayis, D. Givord, and J. Nogues, Nature (London) 423, 850 (2003).

${ }^{12}$ S. Lund, W. A. A. Macedo, K. Liu, J. Nogues, I. K. Schuller, and C. Leighton, Phys. Rev. B 66, 054422 (2002).

${ }^{13}$ L. Ji, J. Lin, and H. C. Zeng, J. Phys. Chem. B 104, 1783 (2000).

${ }^{14}$ E. Cattaruzza, F. Gonella, G. Mattei, P. Mazzoldi, D. Gatteschi, C. Sangregorio, M. Falconieri, G. Salvetti, and G. Battaglin, Appl. Phys. Lett. 73, 1176 (1998).

${ }^{15}$ W. E. Lee and K. P. D. Lagerlof, J. Electron Microsc. Tech. 2, 247 (1985).

${ }^{16}$ C. R. Gorla, W. E. Mayo, S. Liang, and Y. Lu, J. Appl. Phys. 87, 3736 (2000).

${ }^{17}$ B. Wessler, F. F. Lange, and W. Mader, J. Mater. Res. 17, 1644 (2002).

${ }^{18}$ C.-S. Bai, S. Soled, K. Dwight, and A. Wodl, J. Solid State Chem. 91, 148 (1991).

${ }^{19}$ F. Tielens, M. Calatayud, R. Franco, J. M. Recio, J. Pérez-Ramírez, and C. Minot, J. Phys. Chem. B 110, 988 (2006).

${ }^{20}$ A. N. Dobrynin, D. N. Ievlev, K. Temst, P. Lievensa, J. Margueritat, J. Gonzalo, C. N. Afonso, S. Q. Zhou, A. Vantomme, E. Piscopiello, and G. Van Tendeloo, Appl. Phys. Lett. 87, 012501 (2005). 